\title{
A New Method for the Estimation of Hydraulic Permeability, Coefficient of Consolidation, and Soil Fraction Based on the Dilatometer Tests (DMT)
}

https://doi.org/10.2478/sgem-2019-0021

received March 5, 2019; accepted July 17, 2018.

\begin{abstract}
The main issue of the paper is the estimation of soil hydraulic permeability based on the DMT test. DMTA, DMTC and SASK methods performed in the Nielisz dam, Stegny and the SGGW Campus of the Warsaw University of Life Sciences sites are described. The article presents the implementation of the dilatometer Marchetti test (DMT) in the determination of soil fraction and effects of its occurrence in the subsoil, tested in the Nielisz dam located in the Wieprz river valley in the Lublin province, and in various sites in Warsaw (Stegny site and SGGW Campus of the Warsaw University of Life Sciences). In order to acquire the needed data, the flat dilatometer test (DMT) method was used. A direct and indirect pressure methodology of interpreting soil swelling was characterized in the article. The paper shows the possibilities of determining sand, silt and clay soil fractions based on $p o$ and $p_{1}$ pressures from dilatometer tests (DMT) and the effective $\left(\sigma^{\prime}{ }_{v o}\right)$ and total $\left(\sigma_{v o}\right)$ vertical in situ overburden stress. Additionally, the main advantage of this paper is the proposal of use of a new chart to determine hydraulic permeability and soil fraction, based on DMT tests.
\end{abstract}

Keywords: DMT; mineral and organic soils; classification chart, hydraulic permeability; soil fraction.

\section{Introduction}

Over the years, the development of geotechnics has begun using devices that allow for more and more accurate in situ testing. An example of such a device is a dilatometer presented in 1975 by Prof. S. Marchetti. A dilatometer is used

\footnotetext{
*Corresponding author: Simon Rabarijoely, Faculty of Civil and Environmental Engineering, Warsaw University of Life SciencesSGGW, Nowoursynowska 159 St., 02-776 Warsaw, Poland, E-mail: simon_rabarijoely@sggw.pl
}

very often because of its functionality - the measurement is performed in a short time and in an uncomplicated way, and at the same time, the range of results is representative statistics and usually gives a sufficient result, causing the abandonment of additional measuring equipment. Tests made with the use of a dilatometer test became the starting point for the considerations in this article, in which, the technique of their execution and methods of interpretation of the obtained results were discussed in detail.

Flat Marchetti dilatometer is a measuring device first presented in 1975 by Prof. Silvano Marchetti from Italy. The device measured horizontal deformation of the ground and was characterized by an uncomplicated structure - it consisted of a sharpened steel plate and a circular membrane placed at the shoulder. In his scientific work published in 1980, Marchetti described the dilatometer as a device for determining soil properties in situ test and developed empirical correlations between results of the DMT test and soil parameters used for geotechnical design purposes. This original publication, despite the passage of time, is still the basic source for analysing the results of tests carried out with the DMT probe. Further publications have contributed to the popularization of DMT research on a large scale. Currently, they are willingly used for the needs of engineering practice and scientific research activities in over 70 countries.

The study carried out with the Marchetti dilatometer gives three readings: $\mathrm{A}, \mathrm{B}$ and $\mathrm{C}$, on the basis of which, by making further calculations, geotechnical parameters of the soil are determined. The pressure values measured in the field should be corrected with values of DA and DB. The corrections take into account the stiffness of the diaphragm and the zero pressure gauge, and after their introduction, the pressure values are described by the following formulas:

$$
p_{o}=1.05\left(A-Z_{M}+\Delta A\right)-0.05\left(B-Z_{M}-\Delta B\right),[M P a]
$$


- the corrected pressure reading in DMT at $1.10 \mathrm{~mm}$ displacement at the centre of the membrane $p_{1}$

$$
p_{1}=B-Z_{M}-\Delta B,[M P a]
$$

- $\quad$ corrected third reading in DMT $p_{2}$

$$
p_{2}=C-Z_{M}-\triangle A,[M P a]
$$

- material index $I_{D}$

$$
I_{D}=\frac{p_{1}-p_{0}}{p_{0}-u_{0}},[-]
$$

- horizontal stress index $K_{D}$

$$
K_{D}=\frac{p_{0}-u_{0}}{\sigma_{0}^{\prime}},[-]
$$

- dilatometer modulus $E_{D}$

$$
E_{D}=34.7 \cdot\left(p_{1}-p_{0}\right),[M P a]
$$

- water pressure index $U_{D}$

$$
U_{D}=\frac{p_{2}-u_{0}}{p_{0}-u_{0}},[-]
$$

where: $p_{0}$ - the 0.05 corrected pressure reading in DMT, $p_{1}-B$-pressure reading corrected for $Z_{m}$ and $\Delta B$ membrane stiffness at $1.10 \mathrm{~mm}$ expansion to give the total soil stress acting normal to the membrane at $1.10 \mathrm{~mm}$ membrane expansion, $p_{2}-C$-pressure reading corrected for $Z_{m}$ and $\triangle A$ membrane stiffness at $0.05 \mathrm{~mm}$ expansion and used to estimate pore water pressure, $\sigma^{\prime} v o$ - vertical effective in situ overburden stress at the centre of the membrane before insertion of the DMT blade, $u_{0}$ - pore water pressure acting at the centre of the membrane before insertion of the DMT blade (often assumed as hydrostatic below the water table), $Z_{m}$ - gage pressure deviation from zero when vented to atmospheric pressure (an offset used to correct pressure readings to the true gage pressure).

The material index $\left(I_{D}\right)$ is related to the soil behaviour type and not directly to the grain size (Marchetti, [1]). Marchetti observed that in the case of clays, the pressures $p_{0}$ and $p_{1}$ reach similar values, whereas for sands, these values diverge significantly. On this basis, the subsoil was divided into types depending on the value of the material index $I_{D^{\circ}}$

Several methods have been developed to estimate the horizontal consolidation coefficient $c_{h}$ using DMT pressure dissipation tests. The first method was developed by Robertson and Schmertmann in 1988; in response to their publication, Marchetti and Totani published their study in 1989 (e.g., Marchetti, [1]; Lutenegger and Kabir, [2]; Młynarek et al., [3]; Schmertmann, [4]; Marchetti and Totani, [5]; Lechowicz and Rabarijoely, [6]; Bałachowski, [7]; Młynarek et al., [8]; Młynarek et al., [9][10]; Long et al., [11]; Bihs et al., [12];Mayne, [13]; Zawrzykraj et al., [14]). The pressure dissipation tests proposed by the researchers use individual pressure measurements from DMT probing, which have been described in detail earlier. It should be mentioned that only total horizontal stress is measured during dissipation, and not effective stress.

\section{Interpretation methods for DMT dissipation test results}

The DMTA dissipation curves were published by Marchetti as early as in 1986, as part of a publication on the prediction of friction values on a blade of a dilatometer embedded in clays. An evident conclusion after this publication was that the decay rate of $A$ dissipation in soils vary greatly depending on the permeability of the tested soil. In plasticity clays, a large part of the horizontal stresses affecting the dilatometer blade is the water pore pressure. It was easier to calculate as it is not necessary to measure the pore water pressure to determine later the horizontal coefficient of consolidation. The Robertson et al. in $1988^{[15]}$ DMTC method is based on the measurement of the $p_{2}$ closing pressure, while the Marchetti and Totani in 1989 ${ }^{[16]}$ proposal uses a series of readings for the $p_{0}$ pressure. By determining the horizontal coefficient of consolidation, it is possible to later determine the hydraulic permeability of the tested soils.

\subsection{DMTA method}

The dissipation pressure curves $A$ (DMTA) were published by Marchetti as early as in 1986, as part of a publication on the prediction pressure value in clay around the dilatometer blade. The distribution of horizontal stresses largely corresponds to the distribution of pore water pressure; therefore, a logical conclusion was that the approximate relationship would show horizontal stresses and a coefficient of consolidation in horizontal direction. In addition, the simplification of calculations was the fact that it is not necessary to measure the pore water pressure to determine later the coefficient of consolidation in horizontal direction (e.g., Totani et al., [17]; Schnaid et al., [18]). 
The procedure necessary to determine the coefficient of consolidation in horizontal direction by the DMTA method is to measure the dissipation pressure $A$ over time. The dilatometer's blade is stopped at a given depth and a series of $A$ readings is performed at the appropriate time interval. Most often, pressure $A$ is measured in minutes $0.5,1,2,4,8,15,30$ and 60 . The measurement series are placed on a graph. An example of the DMTA decay curve from the Stegny site is shown in Figure 1 A-T, which shows the time distribution of pressure A. The classification is used to later determine the $t_{\text {flex }}$ time, and the time is read at the inflexion point of the curve (e.g., Marchetti and Totani, [5]).

The coefficient of consolidation in horizontal direction $\mathrm{c}_{h}$ can be calculated as follows:

$$
\begin{aligned}
& c_{h}=\frac{7 \mathrm{~cm}^{2}}{t_{\text {flex }}},\left[\frac{\mathrm{m}^{2}}{y r}\right] \\
& k_{h}=\frac{c_{h} \gamma_{w}}{M_{h}},\left[\frac{\mathrm{cm}}{\mathrm{s}}\right]
\end{aligned}
$$

where: $t_{\text {flex }}$ - the time to reach the contraflexure point in the A-log t curve, $k_{h}$ - coefficient of permeability, $M_{h}-$ constrained modulus in horizontal direction, $\gamma_{w}-$ water unit weight.

\subsection{DMTC method}

The assumption of the test is to stop the blade at a given depth and to execute sequences of measurements and readings $A, B$ and $C$ at various time intervals of the measurement sequence. Measurement $C$ is the closing pressure caused by the diaphragm after measurement $B$ returns to the original position by slowly lowering the gas pressure. The time required for this event is about 1 min. The DMTC method is based on the assumption that pressure $p_{2}\left(C\right.$-pressure reading corrected for $Z_{m}$ and $\Delta A$, membrane stiffness at $0.05 \mathrm{~mm}$ expansion, and used to estimate pore water pressure) is equal to the pore water pressure of the soil that adheres to the membrane (e.g., Gillespie et al., [19]; Schnaid et al., [18]).

When preparing the DMTC method, Robertson based his actions on the procedure presented for the CPT probe and compared the results obtained for these two probes. The obtained graph for $p_{2}$ - logt where logt is the time in the logarithmic scale, should show similarity to the dissipation of excess pore water pressure around the dilatometer membrane. $p_{2}$, after complete dissipation, balances with the value of pore water pressure $\left(u_{0}\right)$ (Campanella and

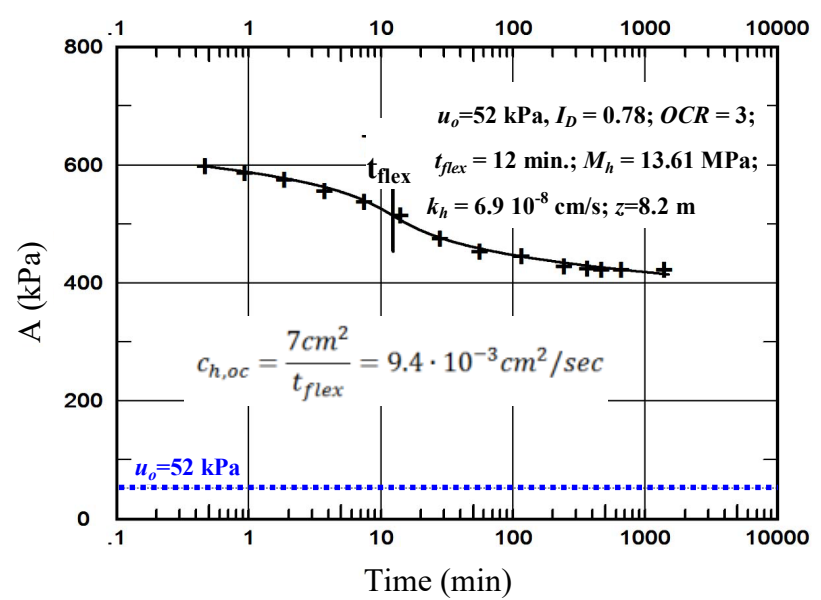

Figure 1: Example of the DMTA decay curve from the Stegny site.

Robertson, [20]). This similarity considers only NC soils, as in OC soils, CPTU dissipation curve is not monotonic

A comparison of the similarities between the shape of the pore water pressure dissipation curve for the DMT test and the theoretical curves developed for CPTU probing helped to develop empirical curves for data from the DMT test. Using these curves, it is possible to derive a formula:

$$
T=\frac{c_{h} \cdot t}{R^{2}},[d a y]
$$

where: $c_{h}$ - coefficient of consolidation in horizontal direction, $R$ - equivalent radius, $T$ - theoretical time factor, $t$ - elapsed time for $\mathrm{U}_{\mathrm{i}} \%$ degree of dissipation.

\subsection{SASK-2 method}

In the SASK-2 method proposed for the determination of hydraulic conductivity of soils, time varying pressures measured by DMT during the return of the deformed membrane to the position of the plane blade (pressures C) are used. The return of the DMT membrane is caused by groundwater pressure (Figure 2). The stream of groundwater flow at a variable pressure gradient depends on the deflection of the membrane geometry and time. To calculate hydraulic conductivity $(k)$, the following formula is proposed:

$$
k=\frac{\frac{Q}{p_{1}-p_{2}} \cdot l}{A \cdot t_{2}} \cdot \ln \frac{p_{1}}{P},\left[\frac{c m}{s}\right]
$$

where: $Q$ - volume of groundwater flow equal to the volume of a sphere section formed from the deformed 
membrane $\left(\mathrm{cm}^{3}\right), p_{1}, p_{2}$ - the maximum pressure needed to deform a membrane of $1.1 \mathrm{~mm}$ and the pressure at the return of the membrane to the plane of the blade $\left(\mathrm{cm} \mathrm{H}_{2} \mathrm{O}\right)$, respectively, $l$ - average range of the ground involved in the groundwater flow $(\mathrm{cm}), A$ - average cross-sectional area of the ground involved in the flow of water $\left(\mathrm{cm}^{2}\right), t_{2}-$ time of groundwater flow (suggested $t_{2}=t_{\text {flex }}$ ).

The most important assumption is that during the return of the DMT membrane, the groundwater flow is variable depending on the changes in the hydraulic gradient. Therefore, the total volume of groundwater $(Q)$ and the time varying hydraulic gradient should be determined. The course of changes in the water volume due to the deflection of the membrane was determined from dilatometer tests used in the spherical soil space (Figure 2).

As a result of membrane deformation, a solid similar to the segment of a sphere is formed; its volume can be calculated from the formula:

$$
Q_{k}=\frac{\pi \cdot h^{2}}{3}\left(3 R-h_{0}\right),\left[\mathrm{cm}^{3}\right]
$$

where: $Q_{k}$ - volume of the sphere segment $\left(\mathrm{cm}^{3}\right), h-$ deflection of the membrane $(\mathrm{cm}), R$ - radius of the sphere $(\mathrm{cm})$ calculated from the formula:

$$
R=\frac{r^{2}-h_{0}^{2}}{2 h},[\mathrm{~cm}]
$$

$r$ - radius of the membrane $(\mathrm{cm})$, ho - membrane deflection.

The dilatometer's membrane radius is $3 \mathrm{~cm}$; therefore, $Q_{k}$ is $1.56 \mathrm{~cm}^{3}$. The value of membrane surface $A$ is 28.27 $\mathrm{cm}^{2}$.

\section{Geotechnical conditions of test sites}

This paper presents the test results of mineral and organic subsoils obtained from the Nielisz site located in the Wieprz river valley in the Lublin province, the SGGW Campus site with the Department of Geotechnical Engineering SGGW, and the Stegny site located in Warsaw, where a laboratory and field testing programme was performed. The location of all analysed objects is shown in Figure 3. The index properties of mineral and organic soils and the grain size distribution curve obtained from laboratory tests for mineral soil from the described sites is presented in Table 1 and Figure 4 (Interim reports ${ }^{[2]}$ ).

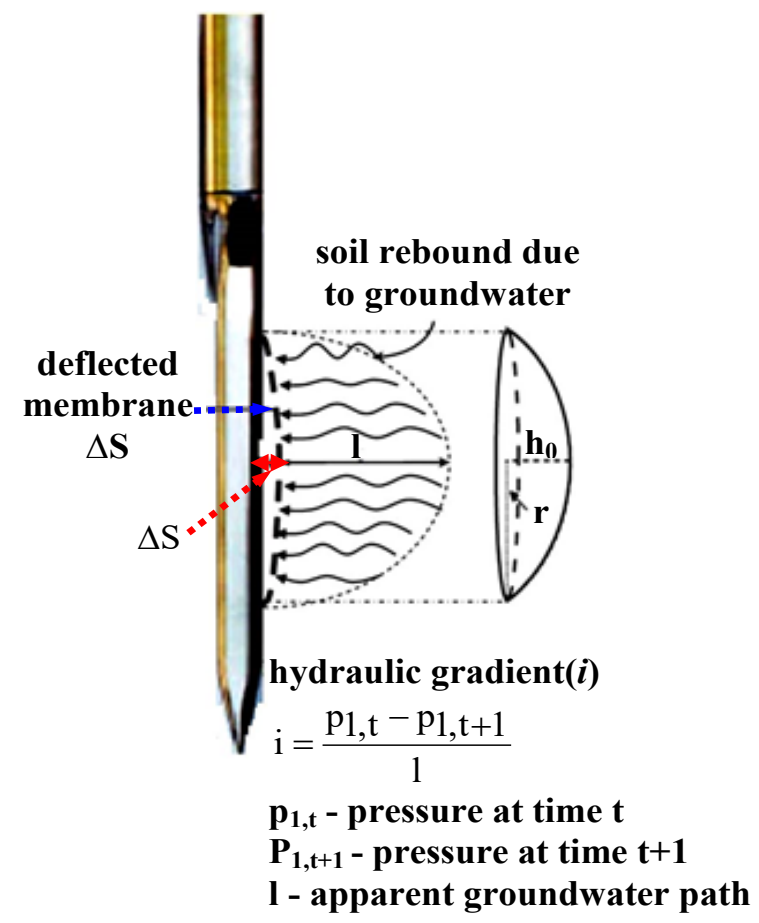

Figure 2: Scheme of groundwater flow to the DMT membrane (DMTC) and assumed segment of sphere (Garbulewski et al., [21]).

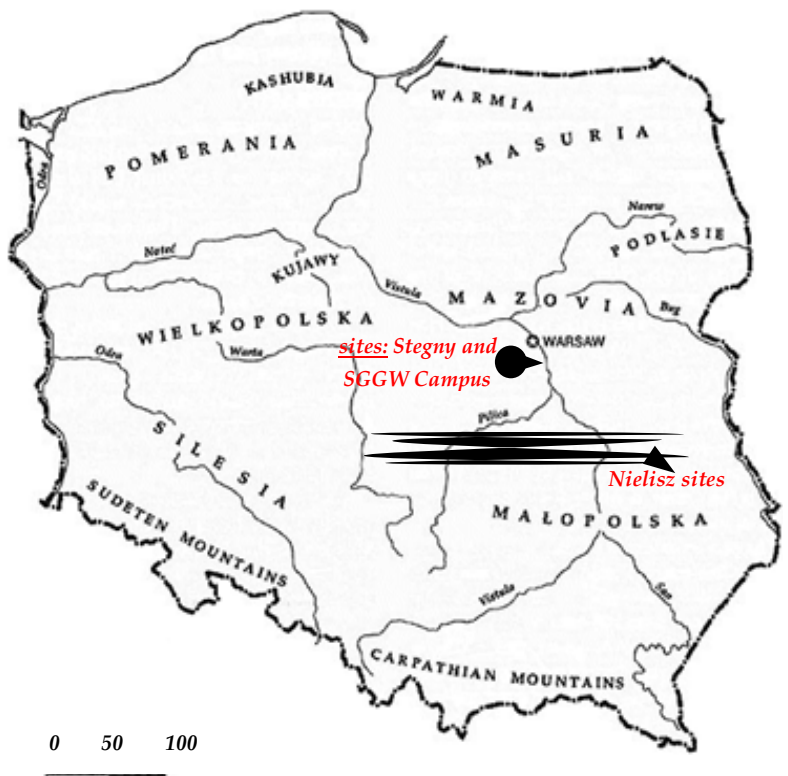

Figure 3: Location of test sites in the region of Poland.

The test results of $p_{0}, p_{1}, p_{2}, I_{D}, K_{D}$ and $E_{D}$ profiles from DMT investigations were used to determine later the practical usefulness of the created chart (Figures 5, 6 and 7). These studies were carried out in the Geoengineering 
Table 1: Index properties of mineral and organic soils at the Nielisz, Stegny and SGGW Campus test sites (Interrim reports [22]).

\begin{tabular}{llllllll}
\hline Sites & Soil type & $\begin{array}{l}\text { Organic } \\
\text { content } \\
\text { lom }(\%)\end{array}$ & $\begin{array}{l}\mathrm{CaCO}_{3} \\
\mathrm{content} \\
(\%)\end{array}$ & $\begin{array}{l}\text { Water content } \\
(\%)\end{array}$ & $\begin{array}{l}\text { Liquid Limit } \\
(\%) \\
(\%)\end{array}$ & $\begin{array}{l}\text { Unit density } \\
\text { of Soil } \\
\rho\left(\mathrm{t} / \mathrm{m}^{3}\right)\end{array}$ & $\begin{array}{l}\text { Specific density of } \\
\text { Soil } \\
\rho_{\mathrm{s}}\left(\mathrm{t} / \mathrm{m}^{3}\right)\end{array}$ \\
\hline Nielisz & Organic mud $\left(\mathrm{M}_{\mathrm{or}}\right)$ & $20-30$ & - & $120-150$ & $130-150$ & $1.25-1.30$ & $2.25-2.3$ \\
& Organic mud $\left(\mathrm{M}_{\mathrm{or}}\right)$ & $10-20$ & - & $105-120$ & $110-130$ & $1.30-1.45$ & $2.30-2.40$ \\
Stegny & Pliocene clays $(\mathrm{Cl})$ & - & - & $19.20-28.50$ & $67.6-88.0$ & $2.1-2.2$ & $2.68-2.73$ \\
$\begin{array}{l}\text { SGGW } \\
\text { Campus }\end{array}$ & Boulder clay (clSa) & - & - & $5.20-20.10$ & $21.9-26.6$ & $2.0-2.2$ & $2.68-2.73$ \\
\hline
\end{tabular}

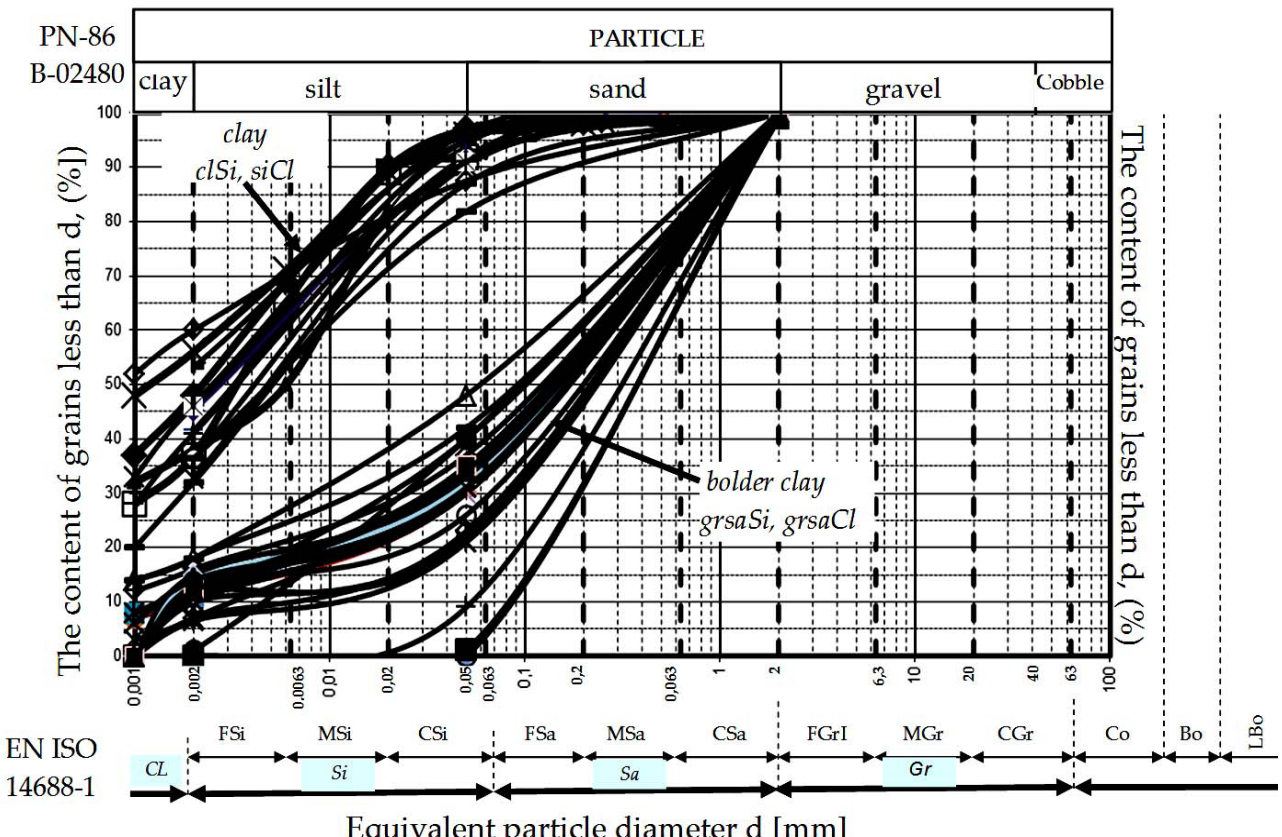

Figure 4: Grain size distribution curve obtained from laboratory tests for mineral soil from the described sites.
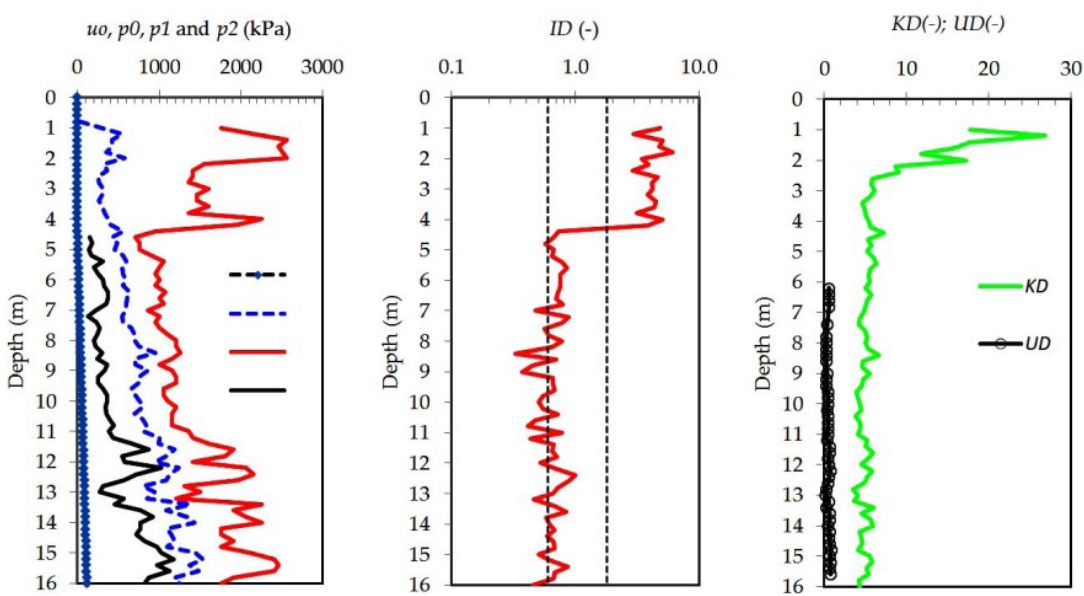

$E D(M P a)$

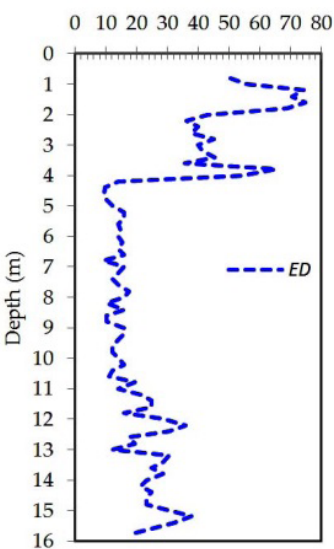

Figure 5: Typical soil profile at the Stegny Pliocene clay site showing the main dilatometer test DMT results. 

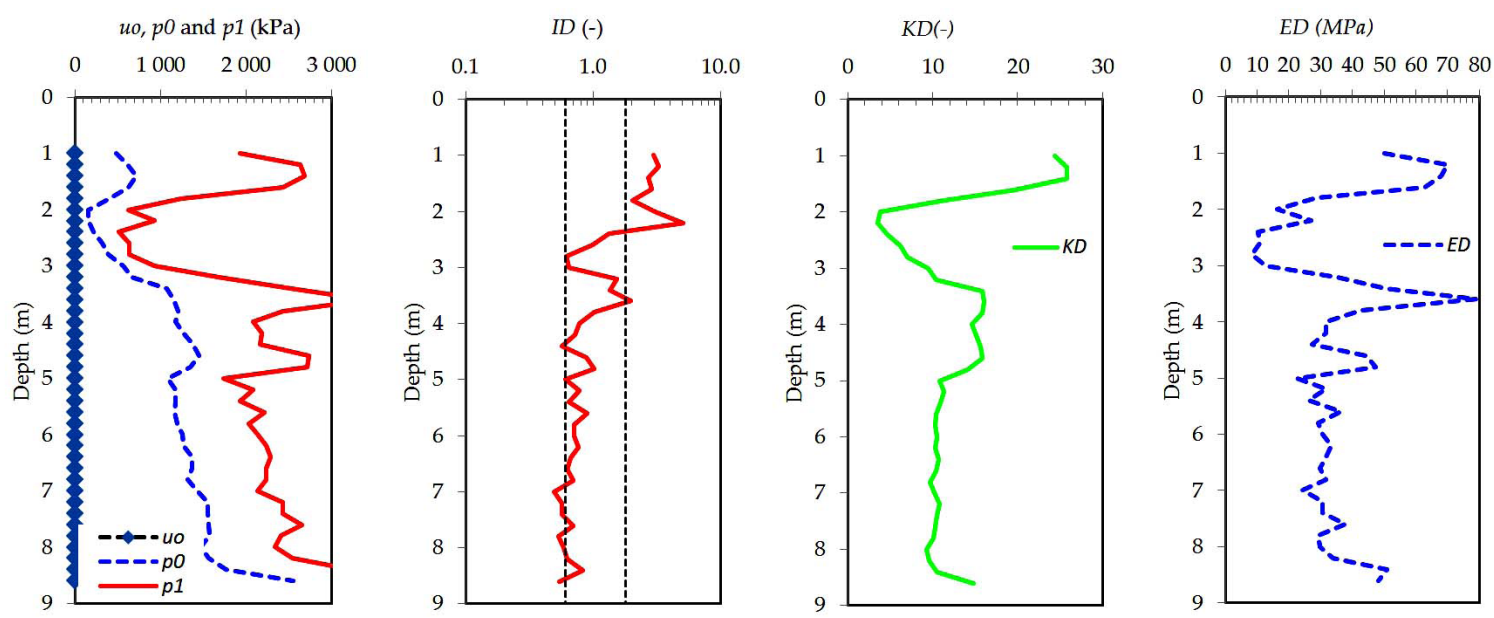

Figure 6: Typical soil profile at the SGGW Campus boulder clay site showing the main dilatometer test DMT results.
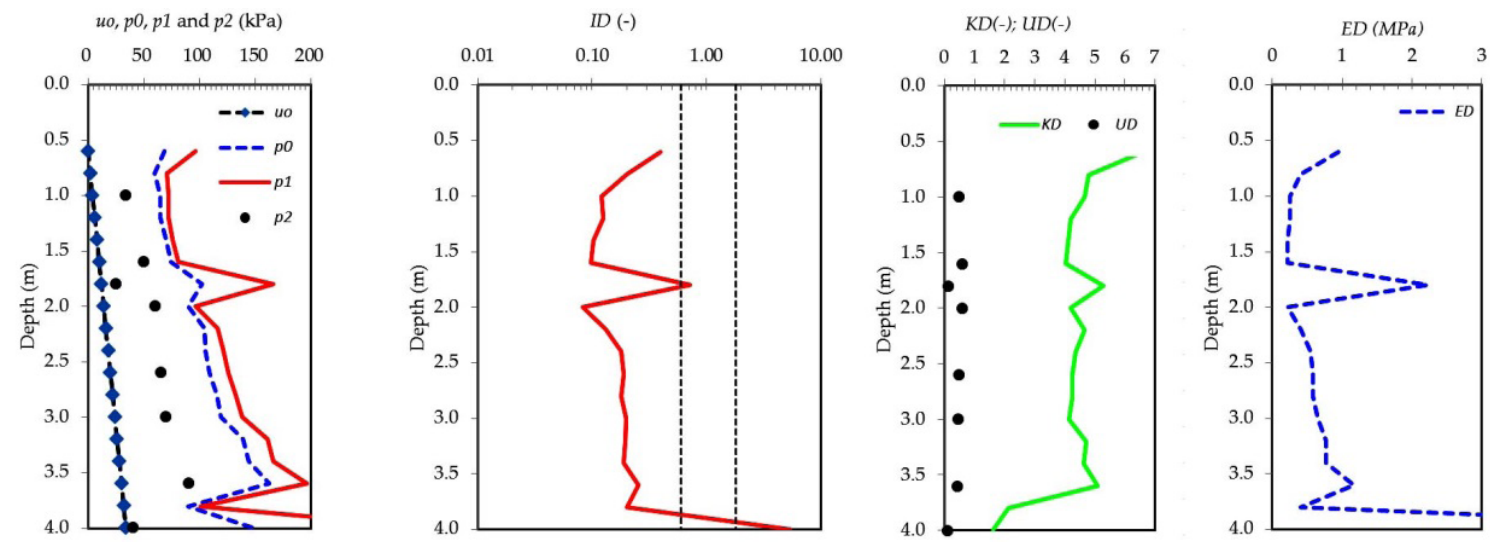

Figure 7: Typical soil profile at the Nielisz dam organic mud and mud site showing the main dilatometer test DMT results.

Department of the Warsaw University of Life Sciences, concerning sites located at the Nielisz dam, the Stegny site and the SGGW Campus, Warsaw University of Life Sciences.

\section{Proposal for determination of the coefficient of vertical consolidation $c_{v}$ and coefficient of hydraulic permeability $\left(k_{h}\right)$ of soils based on dilatometer tests (DMT)}

Obtaining the value of the $c v$ coefficient of vertical consolidation is usually done by performing a standard one-dimensional test, where the time factor of soil compression is obtained. After data acquisition, further analysis is carried out in the curve fitting procedure. The one-dimensional consolidation test is an experimental method and does not entirely coincide with Therzaghi's theory of consolidation, on which the curve selection procedure is based (Sridharan and Nagaraj, [23]). The coefficient of vertical consolidation $\mathrm{cv}$ was determined according to the following formula (Terzaghi et al., [24]).

$$
c_{v}=\frac{0.197 \cdot h^{2}}{t_{50}}
$$

where: $h$ - length of the filtration path [m], $t_{50}$ - time required for $50 \%$ consolidation to occur.

It is possible to determine the coefficient of consolidation $c v$ using the effective vertical overburden stress and the material index $\left(I_{D}\right)$ values. Based on these parameters, a formula was constructed. The advantage of this formula is the fact that it depends, among others, 
on the material index $\left(\mathrm{I}_{\mathrm{D}}\right)$ and the effective vertical stress $\sigma_{v o}{ }_{v o}$, where the tested soils may have the same state but a different $s$ undrained shear strength at different stress histories. Therefore, the relationship is proposed as follows:

$$
C_{v}\left(\frac{m^{2}}{s}\right)=\frac{\sigma_{v}^{\prime A}+B \cdot I_{D}^{C} \cdot\left(D-E \cdot \log \sigma_{v}^{\prime}\right)}{F \cdot I_{D}^{G} \cdot \sigma_{v}^{\prime H}}
$$

where: $A=-1.72 ; B=0.4 ; C=0.17 ; D=0.81 ; E=-0.39 ; F=$ $1143 ; G=-0.2 ; H=1.5 ; I_{D}[-]-$ material index; $\sigma_{v}^{\prime}$ - vertical effective overburden stress [kPa].

Using formula (15), a proposition of the empirical formula enabling the calculation of the vertical coefficient of consolidation $(c v)$ is presented. The original of an empirical dependence requires comparison of its results with the results obtained on the basis of already performed studies. The results of tests, to which the results from the proposed model will be compared, were taken from the archives of the Department of Geoengineering SGGW in Warsaw. Results of tests carried out at the Nielisz dam were analysed. Calculations for the empirical correlation were made in the Solver modulus. Formula (15) has been optimized to describe the results from the comparative tests as close as possible. For this purpose, calculations of relative deviations based on formulas were used.

Maximal Relative Deviation (MRD):

$$
\operatorname{MRD} \max _{i=1,2, \ldots, m}\left|\frac{y_{i}-\widetilde{y_{i}}}{y_{i}}\right| \cdot 100 \%,[\%]
$$

Mean Square Relative Deviation (MSRD):

$$
M S R D=\left[\sqrt{\frac{1}{m} \sum_{i=1}^{m}\left(\frac{y_{i}-\widetilde{y_{l}}}{y_{i}}\right)^{2}}\right] \cdot 100 \%,[\%]
$$

For this purpose, the calculations of relative deviations were based on the formulas for which mean square relative deviation $\mathrm{MSRD}=11 \%$ and the maximum relative deviation $\mathrm{MRD}=17 \%$ were used.

Based on the extrapolation of vertical displacement results (geodesy measurements), total settlement $S 100$ (resulting from the initial consolidation) was determined, which allowed to estimate the value of 550 constituting $50 \%$ of the total settlement value and time $t_{50}$. The calculated values of the coefficient of consolidation $(\mathrm{cv})$ on the basis of field measurements of vertical displacements and the length of the filtration path $h$ and $t_{50}$ were determined according to formula 14.

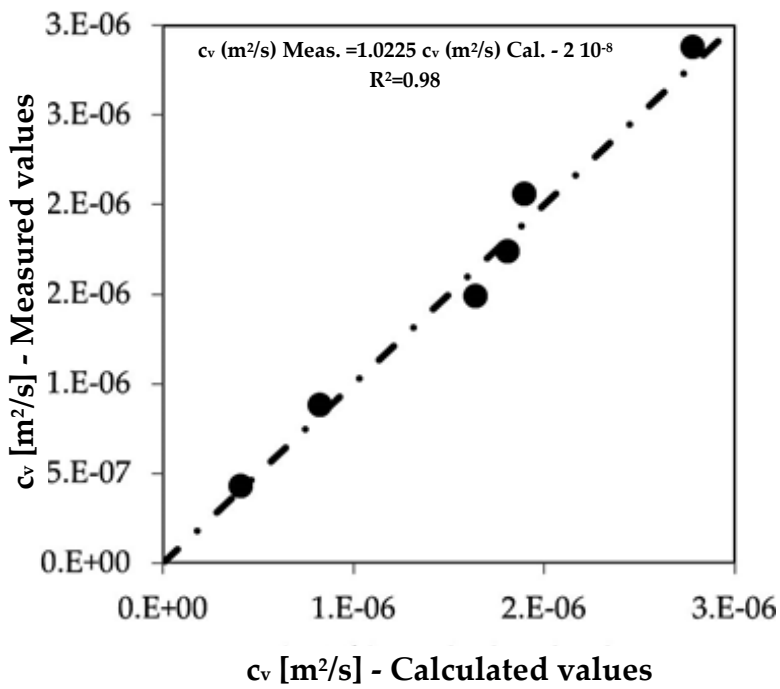

Figure 8: Comparison of test results obtained with the proposed formula and obtained immediately after field tests with a dilatometer.

Figure 8 shows the coefficient of vertical consolidation values calculated from equations (14) and (15) in order to compare the values obtained by various calculation methods. It is recommended to check the effectiveness of this method in another region of Poland.. A comparison of the results measured and calculated using the proposed method is presented in Figure 8. The highest deviation from the obtained results occurs in the profile on the hectometer of $4+50$ upstream at an elevation of 192.50 m.a.s.l, while the most similar results were obtained for the profile on the hectometer of $4+10$ downstream, differing only by $4 \%$.

The last stage of the work was to create a nomogram showing the relationship between hydraulic permeability $k_{h}$ and time $t_{\text {flex }}$. The data used to construct the graph were obtained from DMT tests carried out at the Nielisz dam and at Stegny sites. The main purpose of this chart is to show the dependence between the type of soil, whose soil fractions have been plotted on the graph, the hydraulic permeability, and sometimes $t_{\text {flex }}$, which is an important part of the methods used for determining soil hydraulic permeability parameters with during the exploratory survey tests.

The following equation was used while making the graph

$$
P_{\text {tflex }}=\frac{1.4 \cdot\left(p_{0}-\sigma_{v}\right)}{\sigma_{v 0}^{\prime}},[-]
$$

where: $p t_{\text {flex }}$ - normalized $p_{0}$ (the 0.05 corrected pressure reading in DMT), ov - vertical total in situ overburden stress 


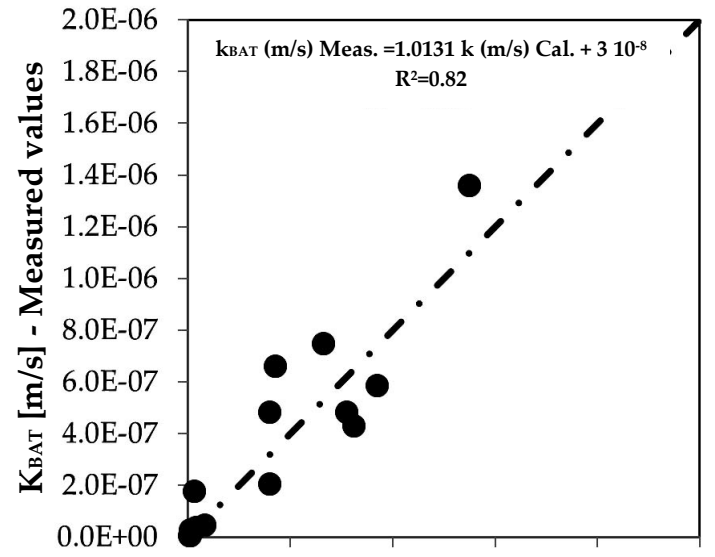

$0.0 \mathrm{E}+004.0 \mathrm{E}-07$ 8.0E-07 1.2E-06 1.6E-06 2.0E-06

\section{$k_{h}[\mathrm{~m} / \mathrm{s}]$ - Calculated values}

Figure 9: Comparison of the hydraulic permeability $\left(k_{h}\right)$ value between the measured and proposed chart from the Nielisz dam and Stegny sites.

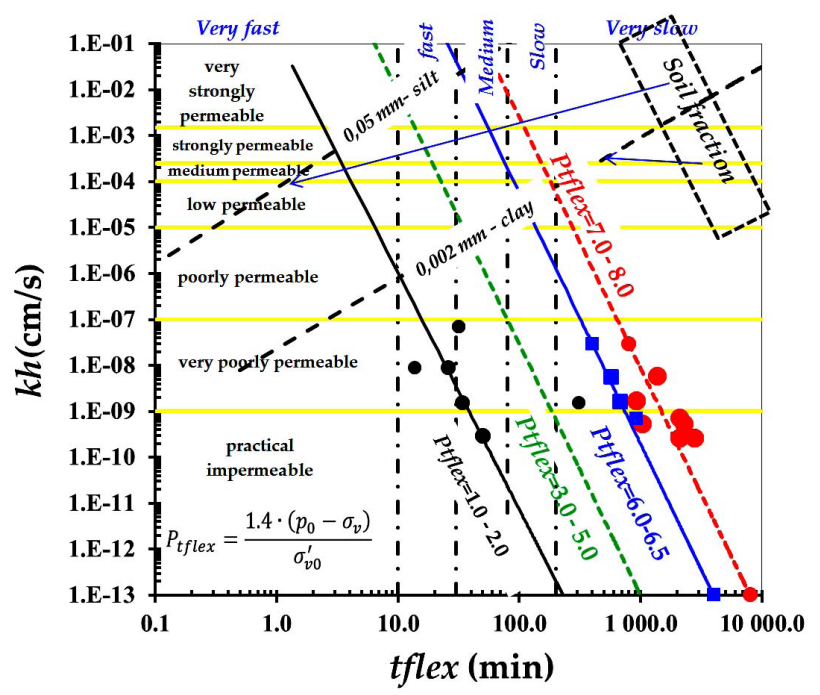

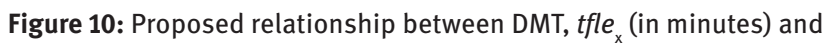
hydraulic permeability of the soil.

The equation is a relationship between vertical effective stress, vertical total stress and $p_{0}$ pressure with an empirical coefficient, expressing the $p t_{\text {flex }}$ function. With basic soil parameters, such as vertical total stress, pore water pressure, and the $t_{\text {flex }}$ time value, hydraulic permeability can be determined. Values of hydraulic permeability presented in Figure 9 were obtained after the proposed DMT tests described in this paper, using the BAT system.

The obtained values of hydraulic permeability from the proposed nomogram chart are comparable to those obtained directly after probing or from the calculation methods. We can see a slight disproportion between the results from the SASK method and the results from the nomogram chart; the values differ by about one order of magnitude. The results obtained for the Stegny site may be slightly inaccurate due to the shortcomings in the $t_{\text {flex }}$ time data for all the measuring depths (Rabarijoely, [25]).

The nomogram can be used in several ways depending on the data available to the user. With $t_{\text {flex }}$ time and the tested soil, the engineer can read the approximate hydraulic permeability (on the nomogram chart moving from point $\boldsymbol{A}$ to $\boldsymbol{B}$, then to $\boldsymbol{C}$ ), or knowing the hydraulic permeability and the thickness of the soil, can read the approximate $t_{\text {flex }}$ time (moving around the nomogram chart from point $\mathrm{C}$ to $\mathrm{B}$, then to $\mathrm{A}$ ). Another application may be the possibility to determine in a given area of the main division of soil fractions and its type, knowing the value of hydraulic permeability and $t_{\text {flex }}$ time. The calculation method for using the nomogram chart is to apply the $P t_{\text {flex }}$ function by means of the effective and total vertical stress of the soil, and the pressure $p_{0}$. The nomogram chart is applied in the case of specifying characteristics for clays or silts, such as those in the sites studied, and soils with a very small grain size. The proposed nomogram chart was used to compare the values of hydraulic permeability obtained from the tests by several methods (Figure 10).

\section{Proposed method for determination of soil fraction of a mineral soil based on the DMT test}

\subsection{Description and analysis of results}

Figures 11, 12 and 13 present the results obtained from borehole and dilatometer tests. Figures 11, 12 and 13 were obtained based on the interpolation technique between a given soil fraction and the pressures $p o$ and $p_{1}$. It contains data used to identify the soil type from the Stegny and SGGW Campus sites. In order to determine the cohesive soil (silt and clay), the material index $I_{D}$ was used. The $I_{D}$ values below 0.6 means clay soil, for a range of 0.6 to 1.8 , is silt soil, while the material index above 1.8 is sand. Figure 10 determines the relationships between the soil fraction and the dilatometer indexes. In the figures showing the correlation of the grain size with pressures $p_{0}$ and $p_{1}$, the range of clay and silt occurrence was also marked. Based on the research from this article, formulas for calculating the percentage of each fraction based on the pressure $p_{0}$ 


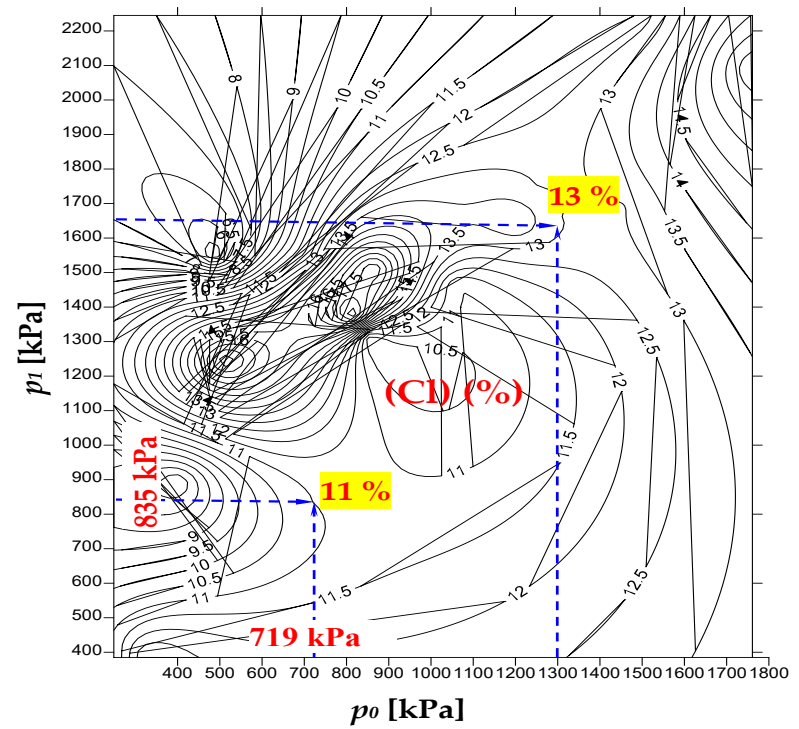

Figure 11: Pressure dependencies $p 0$ and $p 1$ together with isolines to determine the clay fraction

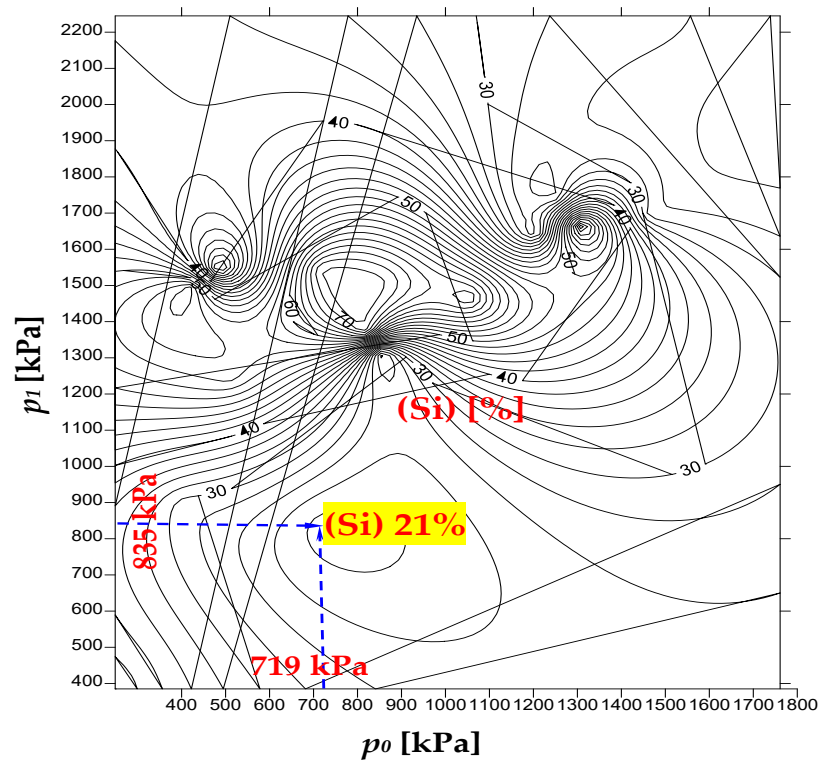

Figure 12: Pressure dependencies $p 0$ and $p 1$ together with isolines to determine the silt fraction.

and $p 1$ obtained from dilatometer tests can be proposed. These formulas are the mean equations obtained from the dataset of each site for a particular type of soil. The formulas for the percentage content of clay, silt and sand fractions are presented in Figures. 11, 12 and 13 for clay and silt soils. The development of these formulas is aimed at approximate determination of the fraction content, thus limiting the performance of additional borehole and laboratory tests. In addition to the formula presented in

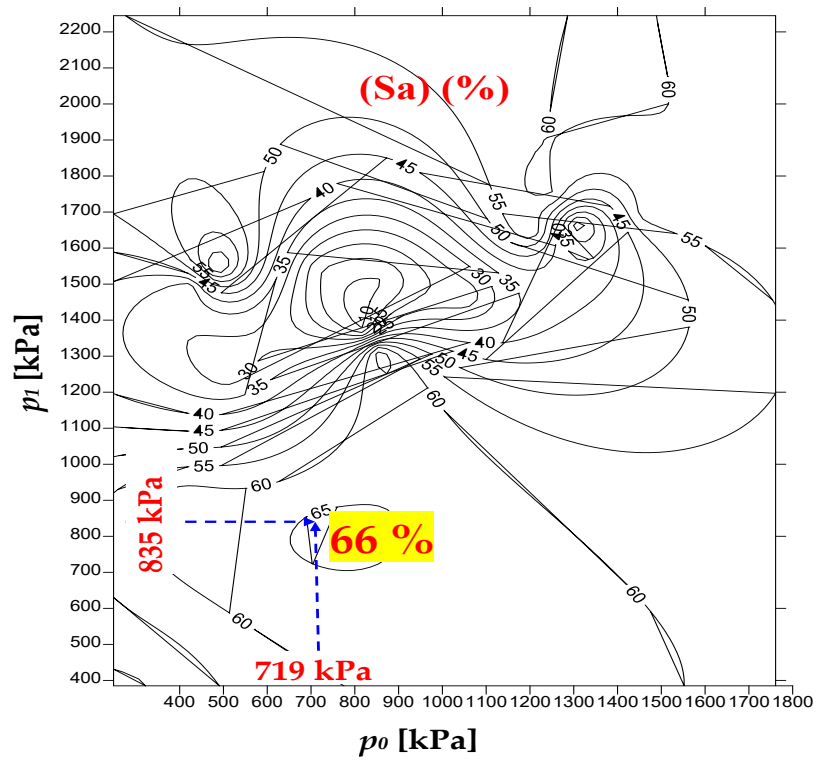

Figure 13: Pressure dependencies $p 0$ and $p 1$ together with isolines to determine the sand fraction.

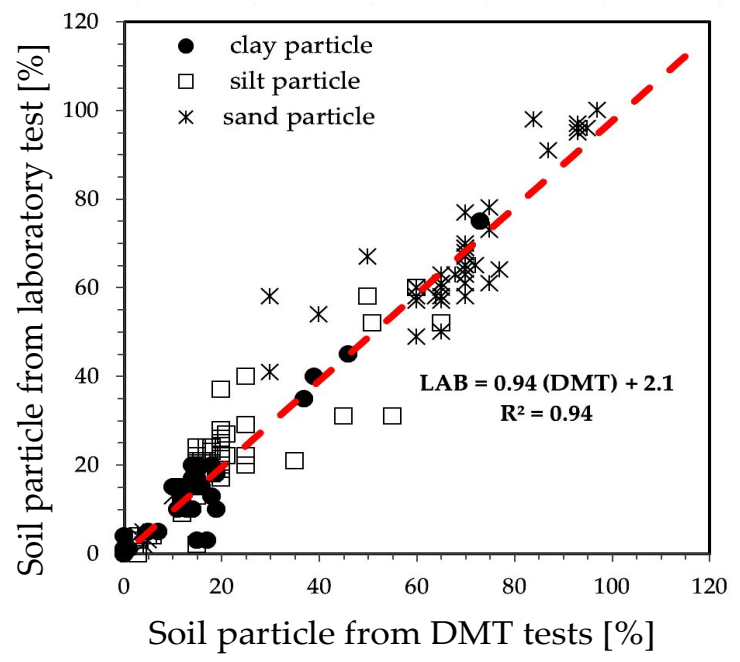

Figure 14: Comparison of the soil fraction obtained from laboratory and dilatometer (DMT) tests results.

the paper, isoline charts for determining clay, silt and sand fractions based on $p_{0}$ and $p_{1}$ pressures obtained from DMT tests are proposed in figures 11, 12 and 13. These two values should be applied to diagrams with isolines. The proposed content of the desired fraction will be the point of intersection of two pressures po and $p_{1}$.

Figure 14 presents the comparison of the measured and calculated results from the proposed formulas and read from the proposed isolines. The results obtained herein are satisfactory due to the fact that when using the proposal to determine the fraction of soil from the 
analysed sites, the analyses carried out herein prove that $85 \%$ of results (Stegny, SGGW Campus) of the grain size are within the limit of the accepted error (7\%). In addition, the percentage difference between the soil fraction obtained in the laboratory and read from the isolines was analysed. In the case of the clay fraction, the difference obtained in all the results was, on the average, only $3.8 \%$. In the case of silt fraction, it was $6.0 \%$, and in the case of sand fraction $-7.0 \%$.

\section{Conclusions}

The dilatometer test (DMT) is widely used for determining the characteristics of soil permeability and the soil fractions content. On the basis of soil analysis performed in three sites (Nielisz, Stegny and WULS-SGGW Campus), the following conclusions may be drawn.

The aim of the article was to provide information on the methods of obtaining soil hydraulic permeability parameters. Largest attention was devoted to the DMTA and DMTC methods and the SASK method, which were used in the computational part of the work. The proposed relationship between DMT, $t_{\text {flex }}$ and soil hydraulic permeability parameters, and normalized pressure, $p_{0}$ was based on the results of dilatometer tests derived from DMT research under the Nielisz dam and in the Stegny site, which has been optimized accordingly. The obtained results are satisfying. The nomogram chart can be used for organic mud, mud, clays, silts or fine sands. The results derived from the archives of the Department of Geoengineering, SGGW were compared with the results read from the proposed nomogram chart. The proposed relationships show features of compliance with geotechnical conditions prevailing in reality.

A proposal of nomogram charts for determining the percentage of each fraction was created based on $p_{0}$, $p_{1}$. These nomogram charts are aimed at obtaining the approximate value of the fraction using the results of dilatometer pressures (DMT). These charts may limit to some extent the number of additional laboratory tests. Thanks to the empirical method established, the excessive amount of research needed to assess soil fraction may be reduced.

Acknowledgments: This work was supported by the Polish Ministry of Science and Higher Education.

Conflicts of Interest: The author declares no conflict of interest.

\section{References}

[1] Marchetti, S. (1980). In situ tests by flat dilatometer. Journal of Geotechnical and Geoenvironmental Engineering, 106(ASCE 15290).

[2] Lutenegger, A. J., \& Kabir, M. G. (1988). Dilatometer C-reading to help determine stratigraphy. Proc. Int. Sym. on Penetration Testing ISOPT-1, Orlando, 1, 549-553.

[3] Młynarek, Z., Niedzielski, A., \& Tschuschke, W. (1983, October). Variability of shear strength and physical parameters of peat. In Proceedings 7th Danube European Conference on Soil Mechanics and Foundation Engineering, Kiszyniów (pp. 93-98).

[4] Schmertmann, J. H. (1986). Suggested method for performing the flat dilatometer test. Geotechnical Testing Journal, 9(2), 93-101.

[5] Marchetti, S., \& Totani, G. (1989). Ch evaluations from DMTA dissipation curves. In Proc. XII Int. Conf. on Soil Mechanics and Foundation Engineering (Vol. 1, pp. 281-286).

[6] Lechowicz, Z., \& Rabarijoely, S. (2000). Dilatometer C-reading to help determine stratigraphy of organic subsoil. Annals of Warsaw Agricultural University. Land Reclamation, 29, 71-78.

[7] Bałachowski, L. (2008). Application des essais au dilatometre Marchetti en sites maritime et fluvial en Pologne. LCPC.

[8] Młynarek, Z., Wierzbicki, J., \& Long, M. (2008, September). Factors affecting CPTU and DMT characteristics in organic soils. In Proc. of XIth Baltic Sea Geotechnical Conference (Vol. 1, pp. 407-417).

[9] Młynarek, Z., Wierzbicki, J., \& Stefaniak, K. (2010, May). CPTU, DMT, SDMT results for organic and fluvial soils. In Proceedings 2nd International Symposium on Cone Penetration Testing (CPt'10). Omnipress, Huntington Beach, California (pp. 455-462).

[10] Młynarek, Z., Wierzbicki, J., \& Wołyński, W. (2018). Use of functional cluster analysis of CPTU data for assessment of a subsoil rigidity. Studia Geotechnica et Mechanica, 40(2), 117-124.

[11] Long, M., Boylan, N., Powell, J., O’Connor, S., \& Donohue, S. (2010). Characterisation of soils beneath flood embankments along the river Thames estuary. In 4th International Conference on Natural and Technical Problems of Environmental Engineering.

[12] Bihs, A., Long, M., Marchetti, D., \& Ward, D. (2010, May). Interpretation of CPTU and SDMT in organic, Irish soils. In 2nd International Symposium on Cone Penetration Testing. Huntington Beach (Vol. 2, pp. 257-264).

[13] Mayne, P. W. (2016). Evaluating effective stress parameters and undrained shear strengths of soft-firm clays from CPT and DMT. Australian Geomechanics Journal, 51(4), 27-55.

[14] Zawrzykraj, P., Rydelek, P., \& Bąkowska, A. (2017). Geoengineering properties of Eemian peats from Radzymin (central Poland) in the light of static cone penetration and dilatometer tests. Engineering geology, 226, 290-300.

[15] Robertson, P. K., Campanella, R. G., Gillespie, D., \& By, T. (1988). Excess pore pressures and the flat dilatometer test. Proc. ISOPT-1, Orlando, FL, 1, 567-576.

[16] Marchetti, S., \& Totani, G. (1989). Ch evaluations from DMTA dissipation curves. In Proc. XII Int. Conf. on Soil Mechanics and Foundation Engineering (Vol. 1, pp. 281-286). 
[17] Totani, G., Calabrese, M., Marchetti, S., \& Monaco, P. (1997). Use of in-situ flat dilatometer (DMT) for ground characterization in the stability analysis of slopes. In XIV International Conference on Soil Mechanics and Foundation Engineering (Vol. 1, pp. 607-610). Balkema.

[18] Schnaid, F., Odebrecht, E., Sosnoski, J., \& Robertson, P. K. (2016). Effects of test procedure on flat dilatometer test (DMT) results in intermediate soils. Canadian Geotechnical Journal, 53(8), 1270-1280.

[19] Gillespie, D., Robertson, P., \& Campanella, R. (1988). Discussion of 'Consolidation After Undrained Piezocone Penetration. I: Prediction' by Mohsen M. Baligh and JacquesNoel Levadoux (July 1986). Journal of Geotechnical Engineering, 114(1), 126-128.

[20] Campanella, R. G., \& Robertson, P. K. (1991). Use and interpretation of a research dilatometer. Canadian Geotechnical Journal, 28(1), 113-126.

[21] Garbulewski, K., Żakowicz, S., Rabarijoely, S., \& Łada, A. (2012). SASK method for testing hydraulic conductivity of soils by flat dilatometer (DMT). Studia Geotechnica et Mechanica, 34(3), 63-72.

[22] Interim Reports-Geotechnical Documentations for Design SGGW Campus Building (2000-2005); Department of Geotechnical Engineering, SGGW: Warsaw, Poland, 20002005. (In Polish).

[23] Sridharan, A., \& Nagaraj, H. B. (2004). Coefficient of consolidation and its correlation with index properties of remolded soils. Geotechnical testing journal, 27(5), 469-474.

[24] Terzaghi, K., Peck, R. B., \& Mesri, G. (1996). Soil mechanics in engineering practice. John Wiley \& Sons.

[25] Rabarijoely, S. (2018). A New Approach to the Determination of Mineral and Organic Soil Types Based on Dilatometer Tests (DMT). Applied Sciences, 8(11), 2249. 